\title{
EFFECT OF AGE, FEMALE MATING STATUS AND DENSITY ON THE BANANA WEEVIL RESPONSE TO AGGREGATION PHEROMONE
}

\author{
W. TINZAARA ${ }^{1,3,4}$, C. S. GOLD ${ }^{1}$, M. DICKE ${ }^{2}$, A.VAN HUIS ${ }^{2}$ and P. E. RAGAMA ${ }^{1}$ \\ ${ }^{1}$ National Agricultural Laboratories Research Institute, P.O. Box 7065, Kampala, Uganda \\ ${ }^{2}$ Laboratory of Entomology, Wageningen University, P.O. Box 8031, 6700 EH Wageningen, The Netherlands \\ ${ }^{3}$ International Institute of Tropical Agriculture, P. O Box 7878, Kampala, Uganda \\ ${ }^{4}$ Bioversity International, P. O. Box 24384, Kampala, Uganda \\ Corresponding author: W.Tinzaara@ cgiar.org
}

(Received 29 August, 2010; accepted 7 April, 2011)

\begin{abstract}
The banana (Musa spp.) weevil (Cosmopolites sordidus (Germar) (Coleoptera: Curculionidae) is a major pest in East Africa causing yield losses of up to 14 metric tonnes per hectare annually. Laboratory and field experiments were conducted to determine whether the response of the banana weevil, Cosmopolites sordidus (Germar) (Coleoptera: Curculionidae) to its aggregation pheromone was influenced by age, female mating status and weevil density. Laboratory bioassays were conducted using a double pitfall olfactometer, while a bucket pitfall trap was used in field experiments. There was no significant $(\mathrm{P}>0.05)$ difference in response to pheromone between immature and mature weevils (males and females) in laboratory bioassays. Forty-day-old weevils had a stronger response to the pheromone than 10-day-old ones under field conditions. The response of unmated weevils to the pheromone was stronger than that of mated weevils, both in the laboratory and field. The percentage of unmated and mated weevils recaptured from 0 and $3 \mathrm{~m}$ were similar but significantly different from $6 \mathrm{~m}$ way from the pheromone baited trap. The response of the weevils to the pheromone was not significantly $(\mathrm{P}>0.05)$ influenced by its previous density.
\end{abstract}

Key Words: Cosmopolites sordidus, mating status, olfactometer

\section{RÉSUMÉ}

Le Coléoptère (Cosmopolites sordidus (Germar) (Coleoptera: Curculionidae) est une importante peste de la banane (Musa spp.) causant de pertes annuelles de rendements allant jusqu' à 14 tonnes par hectare à l'Est de l' Afrique. Des essais au laboratoire et au champ étaient conduits pour déterminer si la réponse des coléoptères, Cosmopolites sordidus (Germar) (Coleoptera: Curculionidae) à leur aggrégation phéromonale était influencée par l'age, le statut sexuel des femelles et la densité des coléoptères. Un olfactomètre à double piège était utilisé au laboratoire, alors qu'un piège en forme de sceau était utilisé au champ. Il n'y avait aucune différence significative ( $P>0.05)$ en terme de réponse aux phéromones entre les coléoptères jeunes et âgés (males et femelles) dans les essais au laboratoire. Les coléoptères âgés de quarante jours avaient présenté une forte réponse au phéromone par rapport à ceux de dix jours d'âge en conditions de champ. Au laboratoire et au champ, la réponse au phéromone des coléoptères non pariés était plus forte que celle des coléoptères pariés. Le pourcentage des coléoptères pariés et non pariés mesuré à 0 et $3 \mathrm{~m}$ était similaire mais significativement différent à $6 \mathrm{~m}$ de distance du piège phéromonal. La réponse de coléoptères au phéromone n'était significativement $(\mathrm{P}>0.05)$ pas influencée par leur densité initiale.

Mots Cles: Cosmopolites sordidus, Statut sexuel, olfactomètre 


\section{INTRODUCTION}

The banana weevil, Cosmopolites sordidus (Germar) (Coleoptera: Curculionidae) is an important insect pest of banana in East Africa (Gold et al., 1999). High pest density can cause yield losses of up to 40-100\% (Rukazambuga et al., 1998) and shorten plantation life span (Gold et al., 2004a). Cosmopolites sordidus adults live up to four years and females have a low fecundity (Gold et al., 2001). The sex ratio is 1:1 (Gold et al., 2001). The weevil rarely flies and seldom crawls more than $50 \mathrm{~m}$ in three months (Gold et al., 2001). Eggs are placed singly within the base of a banana plant (Abera et al., 2000). After hatching, the larvae tunnel into the corm and pseudostem where they develop and pupate. Emerging adults are freeliving, although they are most often associated with banana plants or crop residues (Gold et al., 2004b).

The adults are attracted by banana volatiles (kairomones), especially from cut or damaged corms (Gold et al., 2001). This has been utilised in trapping of weevils using pseudostem residues (Gold et al., 2002). The limitations associated with pseudostem trapping have led to attempts to develop more effective means of trapping, using synthetic pheromones. Budenberg et al. (1993) were the first to report evidence for an aggregation pheromone being released by male $C$. sordidus. Subsequently, Beauhaire et al. (1995) isolated the major component of the pheromone, confirmed its bioactivity, named it sordidin and elucidated its structure including stereochemistry. Ndiege et al. (1996) and Jayamaran et al. (1997) synthesised racemic sordidin, that could be produced at large scale for field-testing. Currently, the pheromone is synthesised in Costa Rica by Chemtica International, which sells it as lures under the trade name Cosmolure+. This pheromone has been tested in Uganda for $C$. sordidus response (Tinzaara et al., 2003) and attracts both male and female weevils. The pheromone-baited trap captures up to 18 times more weevils than a conventional split pseudostem trap in an on-station trial (Tinzaara et al., 2000).
Effectiveness of mass trapping using pheromones may be influenced by, among other factors, the physiological status of a pest (e.g. sexual maturity; insect mating status) (James et al., 1994; Boughton and Fadamiro, 1996; Wertheim et al., 2005). For instance, mated females of the cotton boll weevil, Anthonomus grandis (Boheman), were less responsive to male-produced aggregation pheromone (grandlure) than virgin females in laboratory bioassays and in field tests (Hardee et al., 1969). In insect species in which virgin females are trapped, the reduction in the subsequent generation may be directly related to the proportion removed from the population. If females are trapped after mating and oviposition has occurred, the efficiency of this control method decreases. If males are trapped, a very large proportion probably would have to be captured before there is a noticeable impact on the next generation. This is true for many insect species (including members of the Rhynchophorinae) in which both males and females are capable of mating many times (Hardee et al., 1969).

A high population density of the target insect can also limit the control efforts, especially if there is competition between synthetic and insect produced plumes (Howse et al., 1998). Mass trapping tends to be more effective at low population densities as was reported for Anthonomus grandis (Legget et al., 1989). The relationship between insect density and response to pheromone lures has not been investigated for $C$. sordidus.

Cosmopolites sordidus adults become sexually mature 20 days after emergence (Uzakah, 1995). Although sordidin-baited lures are known to attract both female and male weevils (Alpizar et al., 1999; Tinzaara et al., 2000), there is lack of information on the effect of age and female mating status of $C$. sordidus on catches in pheromone-baited traps. If mature and mated individuals do not respond to the pheromone lures in the field, then trapping will only have limited success for an insect like $C$. sordidus.

This study was undertaken to ascertain whether $C$. sordidus' response to the 
aggregation pheromone is determined by differences in age, female mating status and density.

\section{MATERIALS AND METHODS}

Study site. Laboratory studies were conducted in a dark room $(5 \mathrm{~m} \times 3 \mathrm{~m} \times 4 \mathrm{~m})$ at the International Institute of Tropical Agriculture (IITA) Sendusu Farm (0³5’ 32³2’E, 1260 m above sea level (m.a.s.1.)) in Uganda. The windows and the door of the room were tightly sealed with black polythene sheets. Ambient temperatures in the laboratory ranged from 22 to $28^{\circ} \mathrm{C}$. During the study period, the room had a red light from a red Philips 40 watts bulb that was switched on during all experiments to facilitate taking of data without disturbing the test insects. Measurements were conducted between 9.00 and 17.00 hours.

A field experiment to examine the response of $C$. sordidus to the pheromone was conducted at the Kawanda Agricultural Research Institute (KARI) in Uganda $\left(0^{\circ} 25^{\prime} \mathrm{N}, 32^{\circ} 51^{\prime} \mathrm{E}, 1190\right.$ m.a.s.1.) located $12 \mathrm{~km}$ north of Kampala, and at Sendusu on-station farm $\left(0^{\circ} 32^{\prime} \mathrm{N}, 32^{\circ} 35^{\prime} \mathrm{E}\right.$, 1260 metres above sea level) (m.a.s.l.), located $28 \mathrm{~km}$ northeast of Kampala (Uganda). Both sites have two rainy seasons (March-May and September-November) with mean annual rainfall of 1200-1250 mm and daily mean temperature of $21{ }^{\circ} \mathrm{C}$.

Pheromone sources. The pheromone lures for use in laboratory and field were obtained from ChemTica International in San Jose, Costa Rica. They were sealed in plastic and sent by courier (transit time $<1$ week). They were subsequently stored in a freezer at $4{ }^{\circ} \mathrm{C}$ upon arrival until use. Each pheromone pack contained $90 \mathrm{mg}$ of Cosmolure+ with a release rate of $3 \mathrm{mg} \mathrm{day}^{-1}$ (A.C. Oehlschlager, pers. comm.). They were used in their original package material.

Insects. A culture of $C$. sordidus was established in a shade house at KARI using insects that were trapped using pseudostem traps (Mitchell, 1978) from banana plantations in Masaka District $(130 \mathrm{~km}$ south west of Kampala). Weevils were released into 301 buckets containing pared (chopping off roots and outer layer) corms. After laying eggs on corms for 5-7 days, the adult weevils were removed. The corms were then placed in metallic drums that were covered with a papyrus mat to allow ventilation. Corms were sprayed with water when necessary to maintain an appropriate relative humidity of $70-80 . \%$ using a plastic watering can until adult weevils emerged (after about 50 days). Cultures were established at monthly intervals to raise weevils of different ages.

All weevils used in the experiment were kept in the dark room with the red light on for at least $15 \mathrm{hr}$ prior to being used. Preliminary observations indicated that keeping the weevils in the dark room increased their response in the bioassay. Each weevil was used in a single assay and then discarded.

Double pitfall olfactometer. All laboratory bioassays were conducted using a double pitfall olfactometer modified from the set used by Budenberg et al. (1993). The apparatus consisted of a round plastic basin $(50 \mathrm{~cm}$ diameter, $30 \mathrm{~cm}$ deep) with two $4 \mathrm{~cm}$-diameter holes at the base $2 \mathrm{~cm}$ from each end of the diameter line. Two conical glass flasks protruded through the two holes with their rims aligning well with the cut surface of the basin.

One weevil was placed at the centre of the olfactometer arena in each bioassay set. Each adult was exposed to the odour source(s) for a maximum of 10 minutes, after which the insects were categorised as responders and nonresponders. Weevils found inside the pitfall and those less than $2 \mathrm{~cm}$ from the pitfall were considered to be responsive to the odour source. The sequence of odour sources was randomised over each experimental day. Fresh odour sources were used for every comparison. After testing each odour set, the apparatus was washed with ethanol and air-dried to eliminate contamination.

\section{Sexual maturity of weevil and response to the pheromone}

Laboratory bioassays. Weevils of two different ages were tested in the laboratory for response 
to pheromone lures in the double pitfall olfactometer. Treatments consisted of immature (10-day old) and mature (40-day old) weevils. There were two jars containing odour sources, connected to the olfactometer arena i.e. one jar with the pheromone (1 pack, releasing at a rate $3 \mathrm{mg} \mathrm{day}^{-1}$ ) and the other with clean air (control). A single weevil was placed at the centre of the arena ( $15 \mathrm{~cm}$ from the odour sources). Eighteen weevils from each age/sex category were tested on the same day for their response to the synthetic pheromone. On dissections, the 10day old weevils had small oocytes, while 40day old had mature oocytes.

Weevils used in the study were collected from a rearing culture as described above. Their sex was determined on the basis of punctuation of the rostrum (Longoria, 1968). Female and male weevils were maintained apart until when required for bioassays. The experiment was repeated on four days (i.e a total of 72 weevils were tested per age category per sex), with the sequence of treatments randomised over experimental days.

Field experiment. A field experiment was conducted at KARI in an established banana field (cultivar Atwalira, AAA-EA group) to determine the effect of sexual maturity on weevil response to pheromone lures. Treatments were immature (10-day old) and mature (40-day old) weevils. Each treatment was replicated in three plots of $10 \times 12$ mats (banana plants originating from a common rhizome) at a spacing of $3 \mathrm{~m} \times 3 \mathrm{~m}$. Plots were separated by $10 \mathrm{~m}$ wide alleys. The plots were clean-weeded and mulched with banana leaves. In each plot, weevils were released on (a) banana mats where pheromone traps were placed ( $0 \mathrm{~m} ; 1$ mat per plot); (b) mats $3 \mathrm{~m}$ from pheromone traps (3 mats per plot); and mats $6 \mathrm{~m}$ from pheromone traps (4 mats per plot).

Different-aged weevils were collected from an established weevil culture (described above). These were marked according to age and release point by scratching the elytra with a sharp blade. Eight weevils ( 4 males and 4 females) were released between 18.00 and 19.00 hours at the base of selected mats.
A 101 bucket pitfall trap (Tinzaara et al., 2000) baited with pheromone was placed in the plots one day after releasing the weevils. The traps were placed at the centre of the plot and one pheromone lure was placed in each trap. Pheromone traps were checked daily and weevils recaptured were counted. The sex and distance of release of recaptured weevils were recorded. The experiment was conducted over a period of 30 days. At the end of the sampling period, the percentage of weevils recaptured from the different distances and of the different ages was calculated.

\section{Mating status and weevil response to pheromone}

Laboratory bioassays. The hypothesis that the mating status of females influences response to pheromones was tested in the laboratory. Weevils collected from the established culture immediately after eclosion were sexed. One set of 100 female weevils (virgin) of the same age was kept in a plastic bucket until sexual maturity, while another set was exposed to an equal number of males and kept together until they started egg laying.

Both mated and unmated females were tested in the double pitfall olfactometer. The odour sources (pheromone and clean air) were rotated after testing three weevils in sequence. Twelve weevils of each group (mated and unmated) were tested on the same day and the experiment was repeated five days later.

Field experiment. A field experiment was conducted at the KARI banana field to evaluate the response of female weevils with different mating status and ovarian development to the pheromone baited traps. Treatments consisted of mated (216 wevils) and unmated (216) female weevils. Weevils were collected from the established culture (described above) at KARI. Their sexes were determined immediately after emergence. A batch of females (300) was kept with males in a ration of 1:2 (males: females)(mated weevils) and the other batch (300) was kept without males (virgin weevils). The weevils were then kept in the laboratory for 
a month before release in the field. The weevils were marked according to the mating status and release mat.

Prior to releasing weevils in the field, 20 unmated females and 20 mated females were dissected to determine pre-treatment oocyte numbers, i.e. the numbers of small, medium and mature oocytes.

In the evening (18.00-19.00 hours), six marked females of each mating status were released per mat in each of the four plots on the following mats: (i) one mat where the pheromone trap was placed at $0 \mathrm{~m}$, (ii) four mats at $3 \mathrm{~m}$ from the pheromone trap, and (iii) eight at $6 \mathrm{~m}$ from the pheromone trap.

Pitfall traps baited with the pheromone were placed in the plots as described above. Traps were checked daily and weevils recaptured were recorded according to distance/ mat of release.

\section{Weevil density and response to pheromone}

Laboratory bioassays. The influence of weevil density on response to pheromone was evaluated using a double pitfall olfactometer in the laboratory. Weevil densities tested for each sex were 4 (low density), 8 (medium density) and 16 (high density) per $100 \mathrm{~g}^{-1}$ corm. Weevils collected from the established culture and separated by sex were placed in plastic containers (diameter $30 \mathrm{~cm}$, height $20 \mathrm{~cm}$ ) under three density conditions. Weevils were held under these conditions for $48 \mathrm{hr}$ until use in the bioassay. During the bioassays, one weevil was released at the centre of the arena at a time. Different density treatments were tested on the same day while one sex category was tested per day.

Eight individually-tested weevils per sex constituted a replicate and there were six replicates. The odour sources (pheromones and clean air) were rotated after testing four weevils in sequence in the bioassay.

Field experiment. Treatments in this case included 4,8 , and 16 weevils mat ${ }^{-1}$. These were laid out in a completely randomised design and replicated three times. The experiment was conducted at Sendusu in 8-year old banana (cultivar Atwalira) plots separated by $10 \mathrm{~m}$ wide alleys. Plot size was $5 \mathrm{~m}$ x $5 \mathrm{~m}$ mats at a spacing of $3 \mathrm{~m} \times 3 \mathrm{~m}$. The plots were clean-weeded and mulched with banana leaves.

The resident weevil population size was estimated before releasing the weevils using pseudostem traps (Mitchell, 1978). The mean resident weevil incidence per mat in plots used was $0.1,1.8$ and 4.0 for low, medium and high density plots, respectively. Weevils were released to supplement the existing resident weevil population at a rate of 4,8 , and 16 weevils/ mat for low, medium and high density plots, respectively. Weevils were marked prior to release according to sex and released per mat in the ratio 1:1 (male: female).

A pitfall trap baited with pheromones as described above was then placed in the plots to capture weevils. Traps were checked every three days for 30 days, and weevils captured were recorded according to distance of release and sex for different densities.

Statistical analysis. The mean number of oocytes of mated and unmated females before their release was compared using a student's ttest. In all experiments, data for weevils responding to the odour sources in the field were analysed using a $\chi 2$-test for contingency of Statgraphics Plus Version 7 statistical package.

\section{RESULTS}

\section{Sex and age of weevil on response to the pheromone}

Laboratory bioassays. Orientation responses by males and females to the pheromone over the short distances in the double pitfall olfactometer were similar (Table I). The responses by males $(2 \times 2$ contingency table, $\chi 2=$ $0.22, \mathrm{P}=0.64)$ and females $(\chi 2=0.05, \mathrm{P}=0.82)$ to the pheromone were not dependent on weevil age (sexual maturity). There was no association between sex and age (sexual maturity) of weevils responding to the pheromone $(\chi 2=$ 0.49, $\mathrm{P}=0.48$ ) (Table 1).

Field experiment. In the field trial, larger proportions of the 40-day old weevils were captured in the pheromone-baited traps than for 
TABLE 1. Response of sexually of immature and mature adult $C$. sordidus to pheromones in double pitfall olfactometer under laboratory conditions

\begin{tabular}{llccc}
\hline Weevil sex & Maturity & \multicolumn{2}{c}{ Weevils attracted to } & \% response of weevils \\
\hline \multirow{4}{*}{ Males } & & Pheromone & Clean air & \\
& Immature & 46 & 2 & 66.6 \\
\multirow{4}{*}{ Females } & Mature & 41 & 1 & 58.3 \\
& Immature & 36 & 3 & 54.2 \\
& Mature & 40 & 4 & 61.1 \\
\hline
\end{tabular}

Only weevils found inside the pitfall and less than $2 \mathrm{~cm}$ from the pitfall are presented in the table. Total numbers of weevils tested were 72 . Females and males responded equally $(2 \times 2$ contingency table, $\chi 2=0.49, P=0.48)$

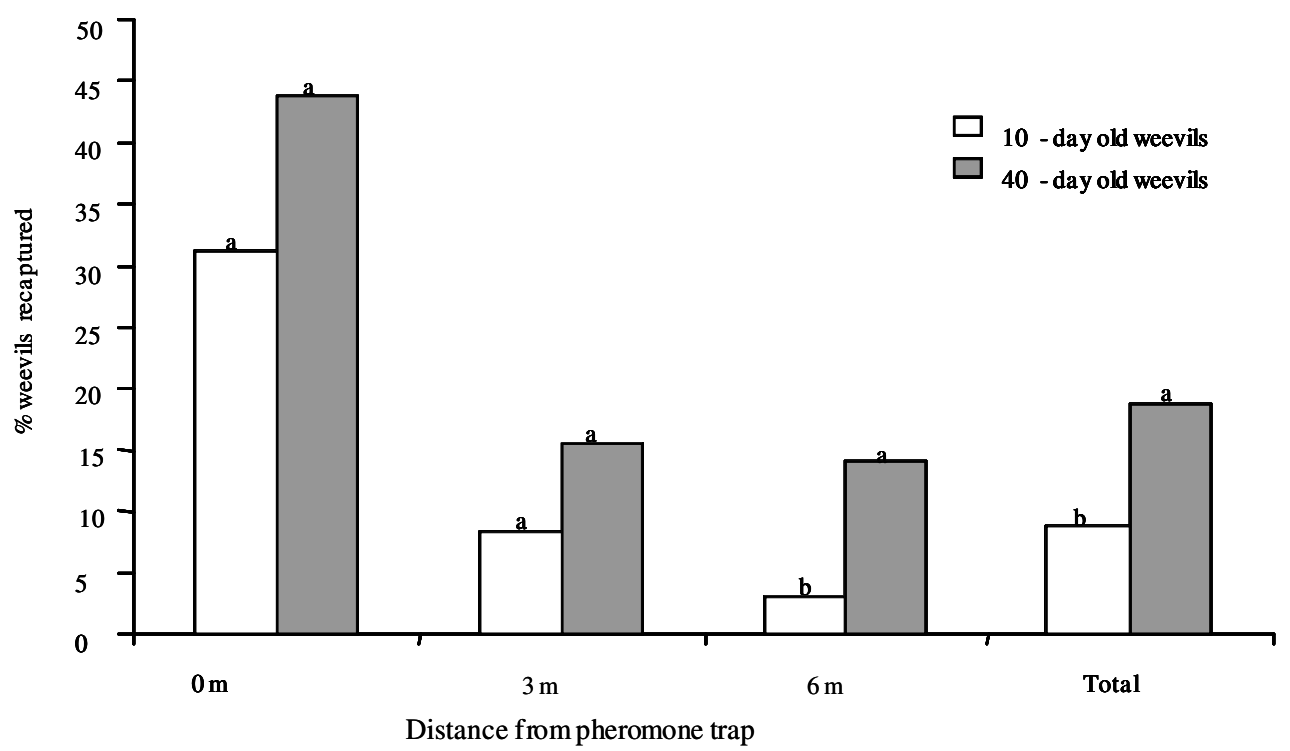

Figure 1. Percentage number of weevils of different ages recaptured from different distances relative to the pheromonebaited trap. Sex ratio of the recaptured weevils was 1: 2.3 for 10-days old, and 1:1.4 for 40-days old weevils. Bars within a distance category with the same letters are not significantly different $(P>0.05,2 \times 2$ contingency table test).

10-day old weevils, at all release distances (Fig. 1). These recapture rates were statistically significant for weevils released $6 \mathrm{~m}$ from traps and for pooled number of weevils. The proportion of weevils recaptured was considerably higher when the weevils were released on the mat near the pheromone trap than when released further away. The sex ratio (male: female) of weevils that responded to the pheromone was 1:2.3 for immature and 1:1.4 for mature weevils.

\section{Mating status and weevil response to pheromone}

Laboratory bioassays. A significantly $(\mathrm{P}<0.05)$ higher proportion of unmated female weevils (57\%) responded to the pheromone than mated ones $(35 \%)$ in laboratory bioassays (Table 2). Both mated and unmated weevils responded significantly higher to the pheromone than to air. Over $40 \%$ of the both mated and unmated weevils were non-responders. 
TABLE 2. Number of mated and unmated female $C$. sordidus weevils found at different positions from the odour sources in the double pitfall olfactometer under field conditions

\begin{tabular}{|c|c|c|c|c|}
\hline \multirow[t]{2}{*}{ Mating status } & \multicolumn{2}{|c|}{ Responding weevils } & \multirow[t]{2}{*}{ Non-responders } & \multirow[t]{2}{*}{$\%$ non-responders } \\
\hline & Pheromone & Air & & \\
\hline Mated & 21 & 7 & 32 & 53 \\
\hline Unmated & 34 & 2 & 24 & 40 \\
\hline
\end{tabular}

Unmated females responded significantly more than unmated females ( $\chi 2=4.9, \mathrm{~d} . \mathrm{f}=1, \mathrm{P}=0.03,2 \times 2$ contingency table test). $n=60$

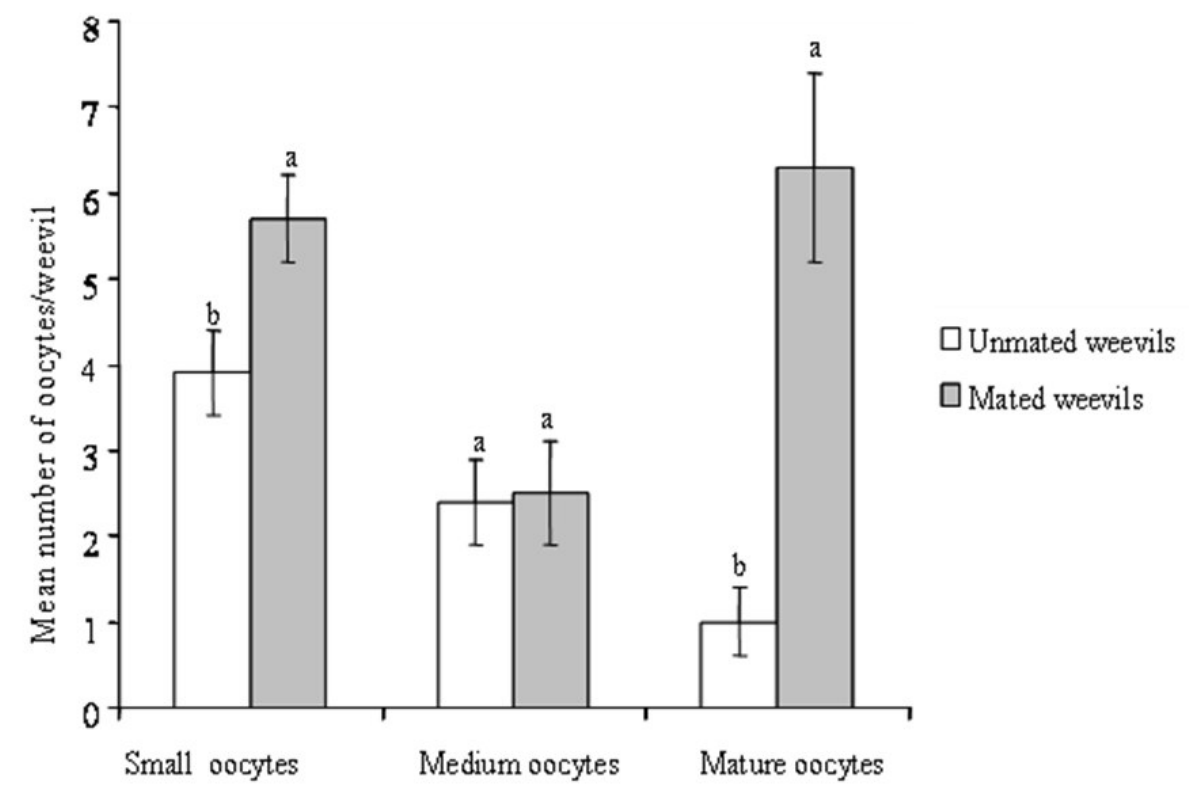

Figure 2. Mean $( \pm S E)$ number of oocytes for mated and unmated females weevils used in the experiment to determine the effect on the mating status on weevil response. Bars for each oocytes category with similar letters are not significantly different (Students t-test, $P>0.05$ ).

Field experiment. Significantly more small and mature oocytes were observed in mated than in unmated weevils prior to release into the field (Fig. 2). The percentages of unmated (24\%) and mated $(19 \%)$ weevils recaptured in pheromonebaited traps in the field were similar $(\chi 2=0.61$, $\mathrm{P}=0.44$ ) (Fig. 3). The percentage recapture of both mated and unmated weevils was similar for those released on the mats where the pheromone was placed and on mats $3 \mathrm{~m}$ from the trap, but the recapture rate was significantly higher for unmated weevils from mats $6 \mathrm{~m}(\chi 2$ $=4.06, \mathrm{P}=0.04$ ) from the trap (Fig. 4).

\section{Weevil and density on response to pheromone}

Laboratory bioassays. Males and females that had been maintained under each density sex (apart or mixed) treatment responded similarly to the pheromone in a double pitfall olfactometer $(\mathrm{P}>0.05, \chi 2$-test). Therefore data for the three sex groups were pooled for final analysis. Weevils that had been kept at each of the three different densities prior to the bioassay did not differ in the degree of attraction to the pheromone (Table 3). Thus, weevil density does 


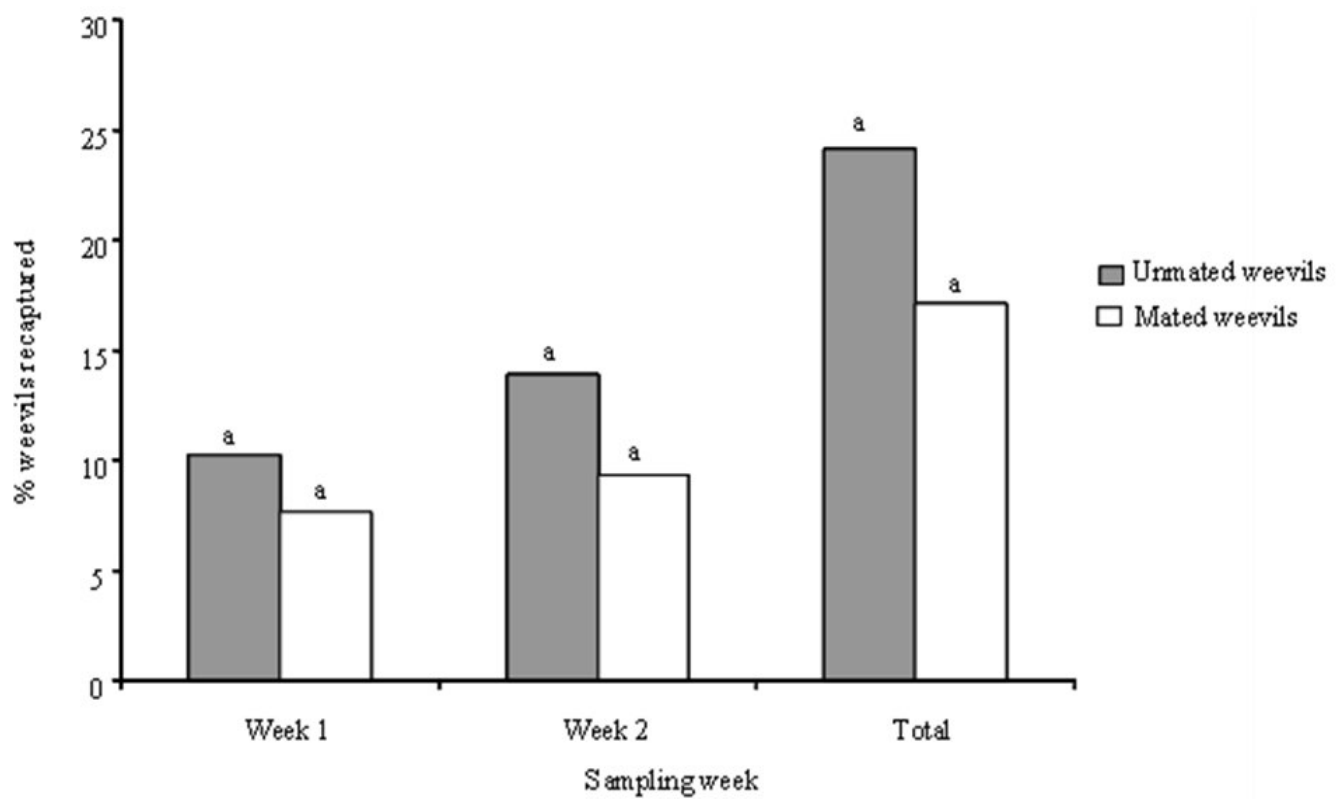

Figure 3. Percentage of mated and unmated $C$. sordidus recaptured in pheromone-baited traps. A total of 216 weevils were released for each mating status in the four plots. Bars with similar letters are not significantly different $(P>0.05,2 \times 2$ contingency table test).

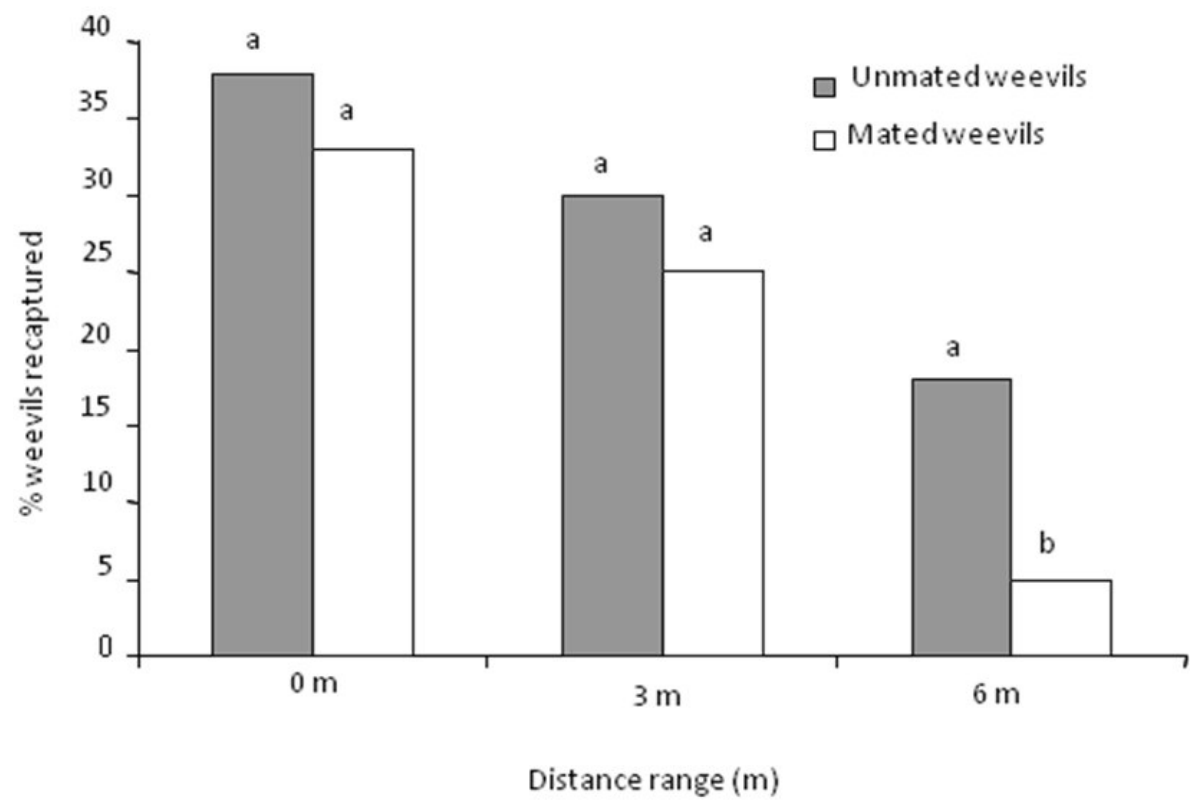

Figure 4. Percentage of mated and unmated weevils recaptured from different distances from the pheromone- baited trap. Bars with similar letters are not significantly different $(P>0.05,2 \times 2$ contingency table test). 
TABLE 3. Number of weevils of different densities that responded to the pheromone in a double pitfall olfactometer under laboratory conditions

\begin{tabular}{|c|c|c|c|c|}
\hline \multirow[t]{2}{*}{ Weevil density } & \multicolumn{2}{|c|}{ Number responding } & \multirow[t]{2}{*}{ Non-responders } & \multirow[t]{2}{*}{$\%$ responders } \\
\hline & Pheromones & Clean air & & \\
\hline Low & 74 & 5 & 65 & 45 \\
\hline Moderate & 82 & 13 & 49 & 34 \\
\hline High & 59 & 8 & 77 & 53 \\
\hline
\end{tabular}

A total of 144 weevils (72 per sex) were tested per density. The number weevils responding to the pheromone of different densities was not significant $(\chi 2=3.65$, d. $f=2, P=0.16,3 \times 2$ contingency table)

TABLE 4. Number and sex ratio of weevils recaptured in pheromone-baited traps from field plots with different densities

\begin{tabular}{|c|c|c|c|c|c|c|}
\hline \multirow[t]{2}{*}{ Treatment } & \multirow{2}{*}{$\begin{array}{c}\text { Mean resident } \\
\text { weevils/ mat }\end{array}$} & \multicolumn{4}{|c|}{ Number of weevils recaptured } & \multirow[t]{2}{*}{ Unmarked $^{2}$} \\
\hline & & Males & Females & $\begin{array}{l}\text { Sex ratio } \\
\text { (M:F) }\end{array}$ & $\begin{array}{c}\% \text { of released } \\
\text { weevils }\end{array}$ & \\
\hline 4 weevils/mat $(400)^{1}$ & 0.9 & 24 & 70 & $1: 2.9$ & 7.8 & 228 \\
\hline 8 weevils/mat (800) & 1.8 & 49 & 132 & $1: 2.7$ & 7.5 & 305 \\
\hline 16 weevils/mat (1600) & 4.0 & 112 & 206 & $1: 1.8$ & 6.6 & 471 \\
\hline
\end{tabular}

${ }^{1}$ The total number of weevils that were added in all banana plots per treatment is indicated in brackets. ${ }^{2}$ Number of resident weevils captured in pheromone traps. The percentage of recaptured weevils from different densisty plots were $\operatorname{similar}(\chi 2=$ $3.33, \mathrm{~d} . \mathrm{f}=2, \mathrm{P}=0.19$ )

not appear to have a significant effect on response to pheromones.

Field experiment. The percentages of marked weevils recaptured from plots with low weevil density $(7.8 \%)$, moderate density $(7.5 \%)$ and high density (6.6\%) were similar (Table 4$)$. Sex ratios of recaptured weevils from the three density plots were similar $(\chi 2=5.2$, d.f $=2$, P $=0.73)$; more females than males were recaptured in all densities.

\section{DISCUSSION}

In the present study, males and females of $C$. sordidus of different ages responded similarly when evaluated for short-distance response to the pheromone Sordidin in a double pitfall olfactometer. Weevils that were mature had a stronger response to the pheromone than immature weevils in the field experiment.
Increased response with age has been previously reported for other coleopteran species (Wertheim et al., 2005) with the converse true for others (Howse et al., 1998). The increased response observed in $C$. sordidus could be explained as mature weevils may benefit from aggregation if it leads to increased mating chances of individuals. Such benefits have been reported for the use of aggregation pheromone in various coleopteran insect species (Wertheim et al., 2005).

In laboratory experiments, we observed that unmated females had a stronger response to the pheromone than mated C. sordidus. Similarly, significantly more unmated females of Metamasius hemipterus were attracted by the aggregation pheromone in laboratory bioassays (Ramirez-Lucas et al., 1996). Searching for males to mate with could be the reason why unmated female responded more than mated female $C$. sordidus to the aggregation 
pheromone. Capturing unmated and fertile females could play a significant role in slowing down the population build up of the pest in a mass trapping approach if other weevils are removed from the population.

In the laboratory studies, there were no significant differences in weevil response to pheromones for male and females previously kept at low, medium and high weevil density. In field experiments, the proportion of weevils recaptured from the different density plots were similar. The results did not support the hypothesis that weevils respond less to pheromones in fields with high weevil density where the pheromone lures may compete with natural pheromone sources. There are, however, reports that show that crowding influence insect response to pheromones (Walgenbach and Burkholder, 1986). Pierce et al. (1983) also found reduced responses by the beetle Oryzaephilus surinamensis to beetle or frass volatiles with increasing population density.

In general, the physiological state of the insects as well as environmental factors may influence their responsiveness to the pheromone. This will affect trap efficacy as well as laboratory bioassay results. The interpretation of laboratory data and trap catches in the field situation must, therefore, depend on knowledge of the behaviour and physiology of insects. Thus in designing a semio-chemical-based management strategy it is important to understand whether physiological factors and population parameters influence insect response.

\section{ACKNOWLEDGEMENT}

The research was funded by the Rockefeller Foundation through a grant to International Institute of Tropical Agriculture and the Wageningen University fellowship Programme. We are grateful to Dr. A. C. Oehlschlager of ChemTica International, Costa Rica, for providing the pheromone lures used in the study. Francis Sebulime and David Mukasa assisted in data collection.

\section{REFERENCES}

Abera, A., Gold, C. S., Kyamanya, S. and Karamura, E. B. 2000. Banana Weevil Cosmopolites sordidus Germar Ovipositional preferences, timing of attack and larval survival survivorship in a mixed cultivar trial in Uganda. Acta Horticulturae 540:87-496.

Alpizar, D., Fallas, M., Oehlschlager, A. C, Gonzalez, L. M. and Jayaraman, S. 1999. Pheromone-based mass trapping of the banana weevil, Cosmopolites sordidus (Germar) and the West Indian sugarcane weevil Metamasius hemipterus L. (Coleoptera: Curculionidae) in banana and plantain. Memorias XIII Reunion ACORBAT, 23-27 November 1998. Guayaquil. pp. 515538.

Beauhaire, J., Ducrot, P. H., Malosse, C., Rochat, D., Ndiege, I. O. and OTIENO, D. O. 1995. Identification and synthesis of sordidin, a male pheromone emitted by Cosmopolites sordidus. Tetrahedron Letters 36:10431046.

Boughton, A. and Fadamiro, H. Y. 1996. Effect of age and sex on the response of Walking Prostephanus truncatus (Horn) (Coleoptera: Bostrichidae) to its maleproduced Aggregation Pheromone. Journal of Stored Products Research 1:13-20.

Budenberg, W. J., Ndiege, I. O. and Karago, F. W. 1993. Evidence for volatile maleproduced pheromone in banana wevil Cosmopolites sordidus. Journal of Chemical Ecology 19:1905-1916.

Gold, C. S., Kagezi, G. H., Night, G. and Ragama, P. E. 2004a. The effects of banana weevil, Cosmopolites sordidus (Germar) damage on highland banana growth, yield and stand uration in Uganda. Annals of Applied Biology 145:261-269.

Gold, C. S., Night, G., Ragama, P. E., Kagezi, G. H. and Tinzaara, W. 2004b. Field distribution for banana weevil adults in cooking banana stands in Uganda. International Journal of Tropical Science 24:242-248. 
Gold, C. S., Okech, S. H. and Noko, E.S. 2002. Evaluation of the pseudostem trapping as a control measure against banana weevil, Cosmopolites sordidus (Coleoptera: Curculionidae). Bulletin of Entomological Research 92:35-44.

Gold, C. S, Pena, J. E. and Karamura, E. B. 2001. Biology and integrated pest management for the banana weevil, Cosmopolites sordidus (Germar) (Coleoptera: Curculionidae). Integrated Pest Management Reviews 6:79-155.

Gold, C. S., Karamura, E. B., Kiggundu, A., Bagamba, F. and Abera, A. M. 1999. Geographic shifts in highland banana (Musa spp., group AAA-EA) production in Uganda. International Journal of Sustainable and Development of World Ecology 6:45-56.

Hardee, D. D., Cross, W. H., Mitchell, E. B., Huddleston, P. M., Mitchell, H. C., Merkl, M. E. and Davich, T. B. 1969. Biological factors influencing responses of the female boll weevil to the male sex pheromone in field and large cage tests. Journal of Economic Entomology 62:161-165.

Howse, P., Stevens, I. and Jones, O. 1998. Insect pheromones and their use in pest management. Chapman and Hall, London, UK. 369 p.

James, D. G., Moore, C. J. and Aldrich, J. R. 1994. Identification, synthesis, and bioactivity of a male-produced aggregation pheromone in assassin bug, Pristhesancus plagipennis (Hemiptera: Reduviidae). Journal of Chemical Ecology 20:32813295.

Jayaraman, S., Ndiege, I. O., Oehlschelager, A. C., Gonzales, L. M., Alpizar, D., Fallas, M., Budenburg, W. J. and Ahuya, P. 1997. Synthesis, Analysis, and field activity of Sordidin, a male-produced aggregation pheromone of the banana weevil, Cosmopolites sordidus. Journal of Chemical Ecology 23:1145-1161.

Legget, J. E., Dickerson, W. A. and Lloyd, E. P. 1989. Suppressing low-level boll weevil populations with traps: Influence of trap placement, grandlure concentration and population level. Southwestern Entomologist 13: 205-216.
Longoria, A. 1968. Diferencias sexuales en la morfologia externa de Cosmopolites sordidus Germar (Coleoptera: Curculionidae). Ciencias Biologia La Habana 1:1-11.

Mitchell, G. A. 1978. The estimation of banana borer population and resistance levels. WINBAN Research and development Technical bulletin No. 2. pp. 34.

Ndiege, I. O., Jayaraman, S., Oehlschlager, A. C., Gonzalez, L. M., Alpizar, D. and Fallas, M. 1996. Convenient synthesis and field activity of a male-produced aggregation pheromone for Cosmopolites sordidus. Naturwissenschaften 83:280-282.

Pierce, A. M., Borden, J. H. and Oehslchlager, A. C. 1983. Effect of age and population density on response to beetle and food volatilers by Orycaephilus surinamensis and $O$. mercator (Coleoptera: Cucujidae). Environmental Entomology 12:1367-1374.

Ramirez-Lucas, P., Rochat, D. and Zagatti, P. 1996. Field trapping of Metamasius hemipterus with systhetic aggregation pheromone. Entomologia Experimentalis et Applicata 80:453-460.

Rukazambuga, N.D., Gold, C.S. and Gowen, S.R. 1998. Yield loss in East African highland banana (Musa spp., AAA-EA group) caused by the banana weevil, Cosmopolites sordidus Germar. Crop Protection 17:581589.

Tinzaara, W., Dicke, M., Van Huis, A., Joop, J. J. A. and Gold, C. S. 2003. Different bioassays for investigating orientation responses of the banana weevil, Cosmopolites sordidus (Germar) show additive effects of host plant volatiles and the synthetic pheromone. Entomologia Experimentalis et Applicata 106:169-175.

Tinzaara, W., Tushemereirwe, W. and Kashaija, I. 2000. Efficiency of pheromones and trap types in the capture of the banana weevil Cosmopolites sordidus Germar in Uganda. Uganda Journal of Agricultural Sciences 5:91-97.

Uzakah, R. P. 1995. The reproductive biology, behaviour and pheromones of the banana weevil, Cosmopolites sordidus Germar (Coleoptera: Curculionidae). Ph.D. 
dissertation. University of Ibadan, Nigeria. pheromone. Environmental Entomology 15: $177 \mathrm{p}$. 733-738.

Walgenbach, C. A. and Burkholder, W. E. 1986. Wertheim, B., van Balaan, E., Dicke, M., and Vet Factors affecting the response of the maize L. E. M. 2005. Pheromone-mediated weevil, Sitophilus zeamais (Coleoptera: aggregation in nonsocial arthropods: an Curculionidae), to its aggregation evolutionary ecological perspective. Annual Review of Entomology 50:321-346. 